\title{
Reducing the Electrical Consumption in the Humidity Control Process for Electric Cells using an Intelligent Fuzzy Logic Controller
}

\author{
Rafik Lasri \\ Dept of Computer Science, \\ Poly-disciplinary Faculty of Larache, \\ University of Abdelmalek Essaâdi, \\ Morocco
}

\author{
Larbi Choukri, Mohammed \\ Bouhorma \\ Dept of Computer Engineering, FST- \\ Tangier, \\ University of Abdelmalek Essaâdi, \\ Morocco
}

\author{
Ignacio Rojas, Héctor Pomares \\ Dept of Architecture \& Computer \\ Technologies \\ University of Granada, Spain
}

\begin{abstract}
The electrical energy distribution uses a huge network to cover the urbanized areas. The network distribution incorporates an important number of electrical cells that ensure the energy transformation. These cells play a fundamental role to ensure a permanent feeding. Thus, the performance of these cells must be optimized. The main problem that affects these cells is the inside humidity that should be controlled permanently to prevent serious damage and power failure. The presented work proposes the use of a powerful intelligent Fuzzy Logic Controller that can online adapt their internal parameters according to the actually state of the controlled plant and auto-learn from the behavior of the plant how the current humidity level can be decreased. The used controller can stabilize the humidity inside the cells within the recommended range by controlling a set of heating resistances installed inside these cells and in the same time ensuring valuable advantages for the electrical energy distribution company. Unlike the rest of the controllers that are used to stabilize moisture. The intelligent controller used in these papers ensures a very precise control with very low power consumption which trains a very significant energy savings in each electrical cell. Knowing that the distribution network incorporates a very large number of electrical cells, the final savings balance would be a very high amount of energy that can be presented economically with significant savings on the electricity bills.
\end{abstract}

Keywords-humidity in electric cells; humidity control; optimization of electrical consumption; intelligent fuzzy logic controller; saving power

\section{INTRODUCTION}

The phenomenon of condensation of atmospheric moisture remains at the center of scientific research for aspects, the positive and the harmful effects. On the positive side, there is the production of water from atmospheric air [1], [2] in order for example to fight against drought, promote agriculture, industrial development and accompany follow demand household water in large cities. On the positive side, there is the production of water from atmospheric air in order for example to fight against drought, promote agriculture, industrial development and accompany follow demand household water in large cities. For adverse effects include the case of bad hygrothermic of buildings [3] which exacerbates the problem of indoor humidity and damage caused by the formation of mold and corrosion. Also moisture condensation poses problems of reliability of electronic components [4], the smooth operation of metal constructions [5], and particularly arcing of electrical installations [6] that cause the interruption of power homes and stopping industrial processes and causing huge financial losses.

So some researchers are interested in determining the dew point [7], [8], temperature at which water vapor in the air condenses and turns into water droplets, and to determine the anti-condensation prevention system best suited. Other researchers have focused on the development of these anticondensation systems and the design of their regulators to optimize their operations; particularly in [9] a Fuzzy-PID controller is developed to control a dehumidifier in high voltage electrical equipment.

In this paper, we will propose the use of an Intelligent Fuzzy Logic Controller (FLC) to optimize the operation of heating resistances installed inside a medium voltage cell to avoid the probable damage due to the formation of the mold and the corrosion. Contrary to the actually used controller and the conventional FLC, the Intelligent FLC will be able to control the environment inside the cells consuming little energy than the remaining controllers.

\section{ELECTRIC CELLS AND CONDENSATION OF ATMOSPHERIC MOISTURE PROBLEM}

Ensure a permanent power supply presents a major concern for the electrical energy distributors, for this, the studies do not cease to lute against different causes of alimentation disruptions. Priming insulators in electric cells low voltage is a common cause of power failure that disrupts the continuity of services provided by electricity distributors.

It's to note here that the role of these cells is to ensure the electricity transmission from the source to consumers by adapting the distributed power via different transformers, which justifies the significant number of these cells along the alimentation network. Therefore, the risk of power cut due to priming of the equipment of these cells is very considerable. The Fig. 1 shows the internal diagram of a cell with its different blocks. A cell consists of three basic systems: 
- The appliances compartment that contain: Medium Voltage (MV) breakers and switch...

- The Medium Voltage bus bar compartment for the electrical connections between several MV cells grouped into tables.

- The connections compartment to MV cables, often used for receiving the measuring sensors.

A fourth compartment used usually to complete this set, it is the control compartment (or Low Voltage, LV box) that contains the protection, monitoring and control units. Priming a switch or circuit breaker causes the power cut out for the all the Medium Voltage cables.

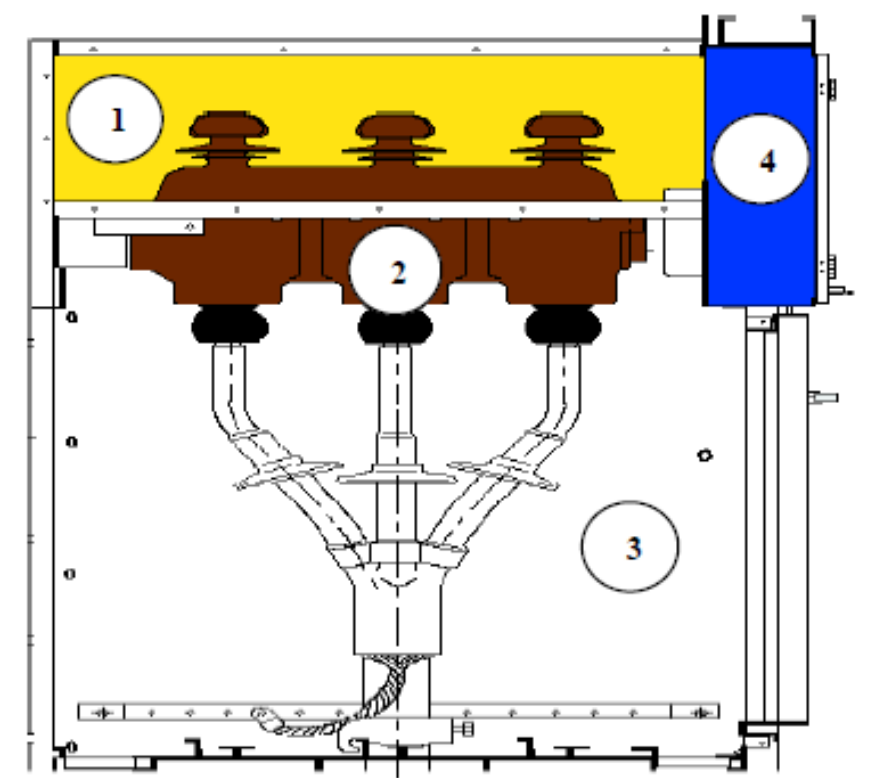

1: Bus bar compartment 2: Vacuum switch 3: Cable compartment 4: Compartment mechanism also serving as low voltage compartment

Fig. 1. The internal diagram of a cell with its different blocks

\section{A. Priming due to the dew point and their risk on the electrical equipment}

Inside the cells (switch or circuit breaker), when the ambient air becomes saturated with water and the metal surfaces are colder, the dew appear on these surfaces (fig.2) which encourages the ionization of the air around the conductors and the appearance of effluvia. This phenomenon liberates molecules such as ozone which recombines with other elements of the ambient air generates nitric acid which oxidizes metals that degrade the insulation and creates leakage paths to ground until priming.

In order to avoid this phenomenon, a heater is installed in the cable compartment of each Medium Volt (MV) cell to warm the sheet metal and the air. This heater (resistance) runs continuously throughout the year causing an important waste of energy and a new risk for the insulation when exceeding the maximum permissible temperature. To avoid all these inconvenient, an intelligent controller will be implemented to ensure a supportive work environment inside the MV cells by calculating dew point from the temperature and the relative humidity measured by a sensor placed in the cable compartment of the MV cells, the intelligent controller will adjust the supply voltage ( 0 to $240 \mathrm{~V})$ of all the heating resistors to heat in an optimal manner inside the cells beyond the critical threshold. Fig. 3 present the proposed control process of the internal Medium Volts cell temperature and humidity. The value of the dew point temperature is given by the formula Henrich Gustav Magnus - Tetens:

$$
T_{D P}=b * \frac{\alpha(T, R H)}{a-\alpha(T, R H)}
$$

while:

$$
\alpha(T, R H)=a * \frac{T}{b+T}+\operatorname{Ln}(R H)
$$

$$
\begin{array}{cl}
\mathrm{T}: \text { Measured temperature }\left({ }^{\circ} \mathrm{C}\right) & \mathrm{a}=17.27 \\
\mathrm{R}_{\mathrm{H}} \text { : Relative humidity }(\%) & \mathrm{b}=237.7^{\circ} \mathrm{C} \\
\mathrm{T}_{\mathrm{DP}} \text { : Dew Point of Moist Air } & 0 \leq \mathrm{T} \leq 60^{\circ} \mathrm{C} \\
& 1 \% \leq \mathrm{R}_{\mathrm{H}} \leq 100 \%
\end{array}
$$
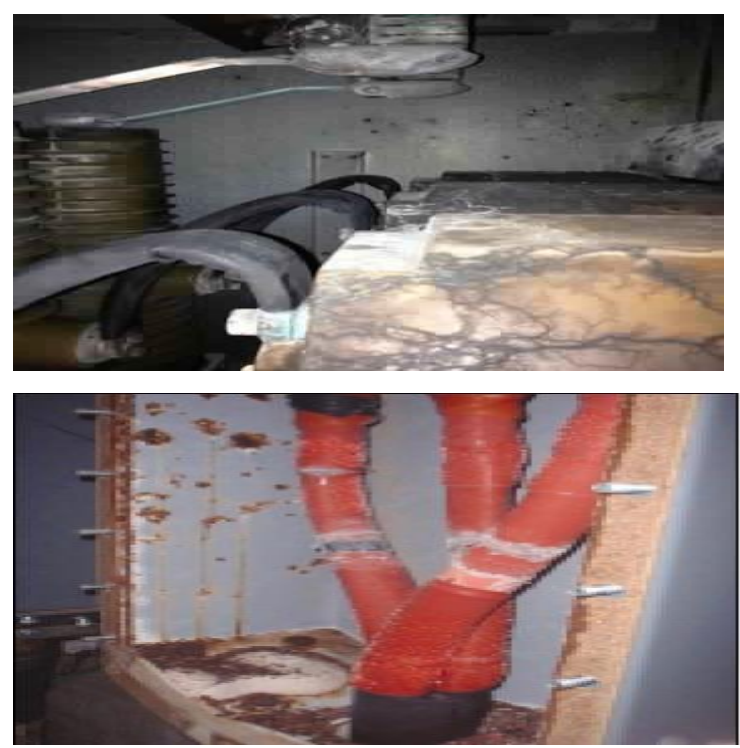

Fig. 2. Apparition of the dew inside the electric cells

\section{IMPLEMENTATION OF THE FUZZY LOGIC CONTROLLER}

The control process presented in these papers is considered as a regular process that not requires sophisticated implementation. Hence, the important parameters to supervise are; the internal temperature of the cell and their variations over the time. The FLC used in this case has two inputs, the temperature difference and their variations; each one of these latter has a set of triangular membership functions imposed by an expert that describes the real state of the plant at this moment. The output of the FLC is the power supply (EV, Electrical Volts) that feeds the heating resistance to establish the required temperature inside the cell. The output space is represented with a set of triangular membership functions imposed too by the expert describing the real state of the plant output. Hence, in this work a Mamdani FLC was used to perform the control process. The used fuzzy rules can be presented as: 


$$
\begin{gathered}
\text { IF } \boldsymbol{T}_{\text {dif }} \text { is } \mu_{\text {critical }} A N D \frac{\text { dTdif }}{\boldsymbol{d} \boldsymbol{t}} \text { is } \mu_{\text {regular }} \\
\text { THEN } \mathbf{V}=\mu_{\text {high }}
\end{gathered}
$$

Once the output fuzzy rule is precised, the defuzzyfucation stage starts by applying the method of the center of gravity as follow:

$$
\hat{\Omega}\left(\vec{z}^{l}\right)=\frac{\sum_{j_{1}=1}^{n_{1}} \sum_{j_{2}=1}^{n_{2}} \cdots \sum_{j_{N}=1}^{n_{N}}\left(S_{j_{1} j_{2} \ldots j_{N}} \cdot \prod_{w=1}^{N} v_{z_{w}^{j_{w}}}\left(z_{w}^{l}\right)\right)}{\sum_{j_{1}=1}^{n_{1}} \sum_{j_{2}=1}^{n_{2}} \cdots \sum_{j_{N}=1}^{n_{N}}\left(\prod_{w=1}^{N} v_{z_{w}^{j_{w}}}\left(z_{w}^{l}\right)\right)}
$$

were $\vec{z}^{l}$ is the input vector at the $k$ instant with $l$ dimension, $S_{j_{1} j_{2} \ldots j_{N}}$ are the activated rules and $v_{z_{w}} j_{w}$ the membership degree.

Fig. 3 present the proposed control process of the internal Medium Volts cell temperature and humidity.

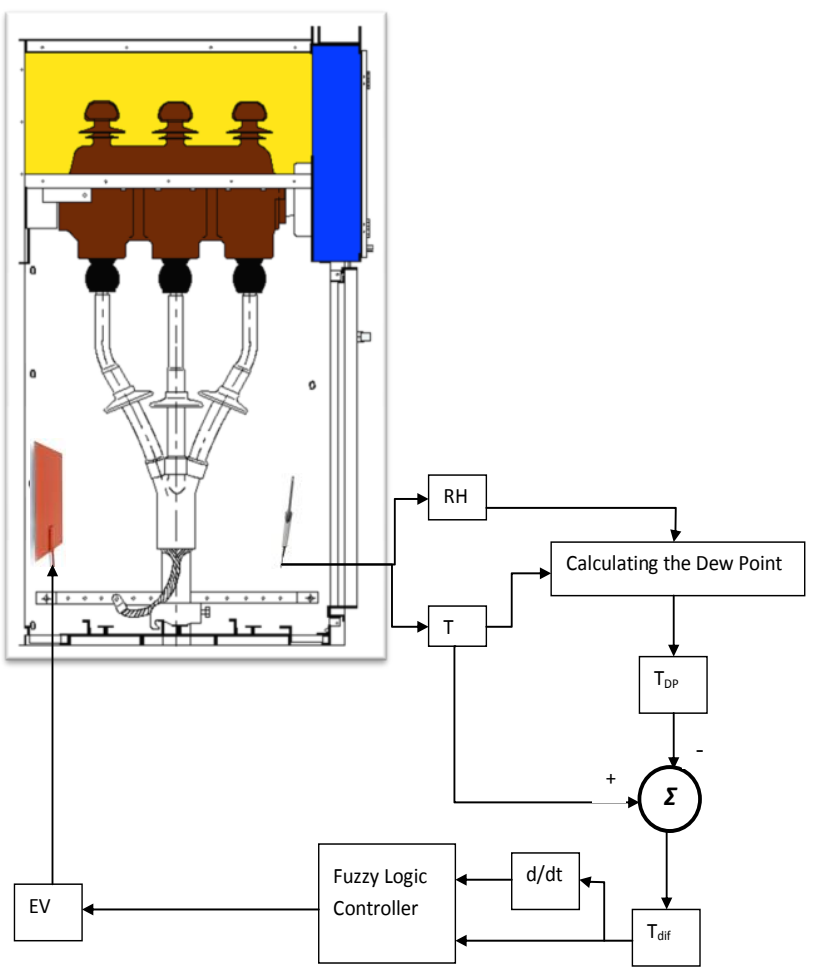

Fig. 3. The proposed control process of the internal Medium Volts cell temperature and humidity

\section{A. Fuzzy Membership Function}

In this control process each input and output variables has a set of membership function that defined as follows:

\section{- Input Variables}

Input 1: Temperature difference $\left(\mathrm{T}_{\mathrm{dif}}\right)$

The difference between the measured temperature $(T)$ and the dew point temperature $\left(\mathrm{T}_{\mathrm{DP}}\right)$, is represented by four membership functions; very critical, critical, optimal, secured and very secured (table I).
TABLE I. THE SET OF MEMBERSHIP FUNCTIONS

\begin{tabular}{|c|c|c|}
\hline Input 1 & Range $\left({ }^{\circ} \mathbf{C}\right)$ & Fuzzy Set Label \\
\hline \multirow{3}{*}{\begin{tabular}{c} 
Temperature difference \\
\multirow{2}{*}{$\left(\mathbf{T}_{\text {dif }}\right)$}
\end{tabular}} & $0-5$ & Very critical \\
\cline { 2 - 3 } & $0-10$ & critical \\
\cline { 2 - 3 } & $5-15$ & optimal \\
\cline { 2 - 3 } & $10-20$ & Secured \\
\cline { 2 - 3 } & $15-20$ & Very secured \\
\hline
\end{tabular}

$$
\begin{aligned}
& \mu_{\text {Very Critical }}(\mathrm{x})=\left\{\begin{array}{c}
1, x<0 \\
1-\left(\frac{x}{5}\right), 0 \leq x \leq 5
\end{array}\right. \\
& \mu_{\text {Critical }}(\mathrm{x})=\left\{\begin{array}{c}
x / 5,0 \leq x \leq 5 \\
2-\left(\frac{x}{5}\right), 5 \leq x \leq 10
\end{array}\right. \\
& \mu_{\text {Optimal }}(\mathrm{x})=\left\{\begin{array}{l}
(x / 5)-1,5 \leq x \leq 10 \\
3-\left(\frac{x}{5}\right), 10 \leq x \leq 15
\end{array}\right. \\
& \mu_{\text {Secured }}(\mathrm{x})=\left\{\begin{array}{c}
(x / 5)-2,10 \leq x \leq 15 \\
4-\left(\frac{x}{5}\right), 15 \leq x \leq 20
\end{array}\right. \\
& \mu_{\text {Very Secured }}(\mathrm{x})=\left\{\begin{array}{r}
(x / 5)-4,15 \leq x \leq 20 \\
1, x>20
\end{array}\right.
\end{aligned}
$$

Fig. 4 presents the input space of the first Input that represent the Temperature difference.

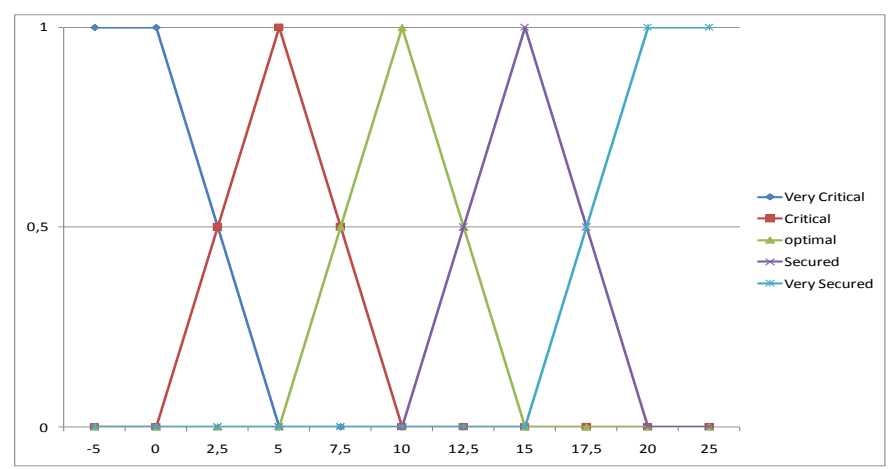

Fig. 4. The input space of temperature difference

Input 2: The temperature difference variation $\left(\frac{\mathrm{dTdif}}{\mathrm{dt}}\right)$

The variation in the temperature difference is represented by four membership functions: very slow, slow, normal, fast and very fast (table II) and Fig. 5 presents the input space of the second Input that represent the variation in the temperature difference.

TABLE II. THE SET OF MEMBERSHIP FunCTIONS

\begin{tabular}{|c|c|c|}
\hline Input 2 & Range $\left({ }^{\circ} \mathrm{C} / \mathrm{s}\right)$ & Fuzzy set \\
\hline \multirow{3}{*}{$\begin{array}{c}\text { Variation in } \\
\text { the temperature difference } \\
\left(\frac{d 7 d i f}{d t}\right)\end{array}$} & $0-0.5$ & Very slow \\
\cline { 2 - 3 } & $0-1$ & slow \\
\cline { 2 - 3 } & $0.5-1.5$ & normal \\
\cline { 2 - 3 } & $1-2$ & fast \\
\cline { 2 - 3 } & $1.5-2$ & Very fast \\
\hline
\end{tabular}




$$
\begin{aligned}
& \mu_{\text {Very Slow }}(x)=\left\{\begin{array}{c}
1, x<0 \\
1-\left(\frac{x}{0.5}\right), 0 \leq x \leq 0.5
\end{array}\right. \\
& \mu_{\text {Slow }}(x)= \begin{cases}x / 0.5, & 0 \leq x \leq 0.5 \\
2-2 x, & 0.5 \leq x \leq 1\end{cases} \\
& \mu_{\text {Normal }}(x)= \begin{cases}2 x-1, & 0.5 \leq x \leq 1 \\
3-2 x, & 1 \leq x \leq 1.5\end{cases} \\
& \mu_{\text {Fast }}(x)= \begin{cases}2 x-2, & 1 \leq x \leq 1.5 \\
4-2 x, & 1.5 \leq x \leq 2\end{cases} \\
& \mu_{\text {Very Fast }}(\mathrm{x})=\left\{\begin{aligned}
2 x-3, & 1.5 \leq x \leq 2 \\
1, & x>2
\end{aligned}\right.
\end{aligned}
$$

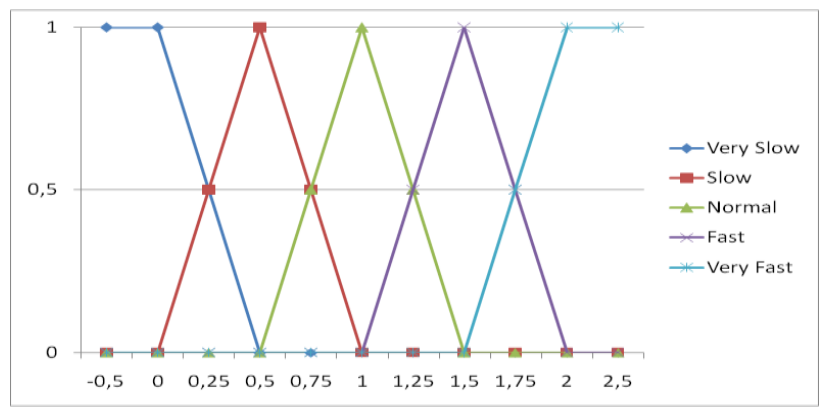

Fig. 5. The input space of the variation in the temperature difference

\section{- Output Variable: Supply signal}

The supply signal is an AC voltage applied to the heating resistor to provide adequate power to prevent condensation of moisture. The output membership function space is represented by using five membership functions: very low, low, regular, high, and very high (table III). Fig. 6 presents the output space that represents the supply power.

TABLE III. THE SET OF MEMBERShIP FunCTIONS

\begin{tabular}{ccc}
\hline \hline Output & Range (Volt) & Fuzzy set \\
\hline & $0-60$ & very low \\
Supply signal (V) & $0-120$ & low \\
& $60-180$ & regular \\
& $120-240$ & high \\
& $180-240$ & Very high \\
\hline
\end{tabular}

$$
\begin{aligned}
& \mu_{\text {Very Low }}(\mathrm{x})=\left\{1-\left(\frac{x}{60}\right), \quad 0 \leq x \leq 60\right. \\
& \mu_{\text {Low }}(x)=\left\{\begin{array}{cl}
x / 60, & 0 \leq x \leq 60 \\
2-x / 60, & 60 \leq x \leq 120
\end{array}\right. \\
& \mu_{\text {Regular }}(x)=\left\{\begin{array}{c}
\left(\frac{x}{60}\right)-1,60 \leq x \leq 120 \\
3-\left(\frac{x}{60}\right), 120 \leq x \leq 180
\end{array}\right. \\
& \mu_{\text {High }}(\mathrm{x})=\left\{\begin{array}{l}
\left(\frac{x}{60}\right)-2,120 \leq x \leq 180 \\
4-\left(\frac{x}{60}\right), 180 \leq x \leq 240
\end{array}\right. \\
& \mu_{\text {Very High }}(\mathrm{x})=\left\{\left(\frac{x}{60}\right)-3, \quad 180 \leq x \leq 240\right.
\end{aligned}
$$

\begin{tabular}{|c|c|c|c|}
\hline & \multicolumn{2}{|c|}{ Inputs } & \multirow{2}{*}{$\frac{\text { Output }}{\text { Supply signa }}$} \\
\hline & Idif & $\frac{d T d i f}{d t}$ & \\
\hline 1 & very critical & very slow & Very high \\
\hline 2 & very critical & slow & Very high \\
\hline 3 & very critical & normal & Very high \\
\hline 4 & very critical & fast & high \\
\hline 5 & very critical & very fast & regular \\
\hline 6 & critical & very slow & Very high \\
\hline 7 & critical & slow & Very high \\
\hline 8 & critical & normal & high \\
\hline 9 & critical & fast & regular \\
\hline 10 & critical & very fast & low \\
\hline 11 & optimal & very slow & Very high \\
\hline 12 & optimal & slow & high \\
\hline 13 & optimal & normal & regular \\
\hline 14 & optimal & fast & low \\
\hline 15 & optimal & very fast & Very low \\
\hline 16 & secured & very slow & High \\
\hline 17 & secured & slow & Regular \\
\hline 18 & secured & normal & Low \\
\hline 19 & secured & fast & Very low \\
\hline 20 & secured & very fast & Very low \\
\hline 21 & very secured & very slow & Regular \\
\hline 22 & very secured & slow & Low \\
\hline 23 & very secured & normal & Very low \\
\hline 24 & very secured & fast & Very low \\
\hline 25 & very secured & very fast & Very low \\
\hline
\end{tabular}

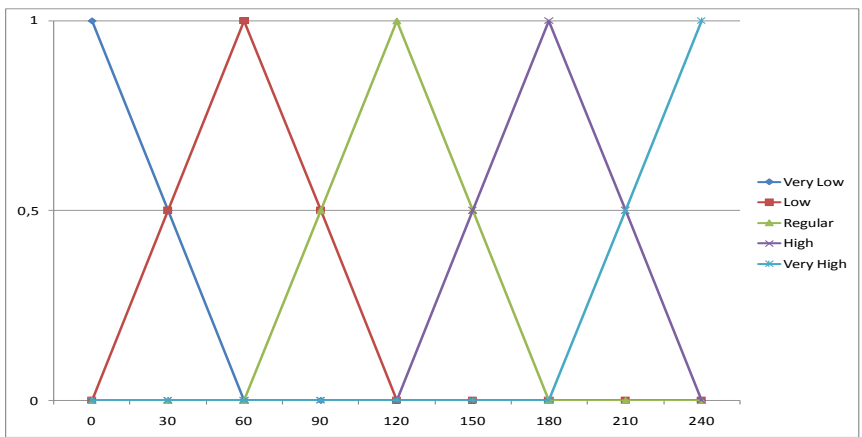

Fig. 6. The output space that represents the supply power

\section{B. Fuzzy Rules Base}

The implemented controller has two inputs, each one of them has five memberships function that cover the variation range of inputs. Therefore, the fuzzy rules base is $5 \times 5$ matrix that represent the output state of each fuzzy rule (table IV).

TABLE IV. THE FUZZY RULES OF THE FLC

\section{THE IMPLEMENTATION OF THE INTELLIGENT FUZZY LOGIC CONTROLLER}

The main objective of this work is to preserve the continuous operation of the electrical cells by consuming very less power. According to the experts, the humidity is the principal factor that can shut down the electrical cells 
operation. For this reason a permanent control of the inside humidity is highly needed. In real case, the humidity is reduced by a heating resistances installed in the electrical cells. The feeding signal of these resistances is controlled by an On/Off controller to keep the indoor temperature within the safe range, the used controller can adjust the indoor temperature and avoid probable moisture risks but in the same time consuming an important amount of energy who represents a supplementary charge for the company expenses. For that reason, the On/Off controller should be substitute with another controller who can follow the state of the controlled plant and predicts suitable output without wasting the electrical energy. The intelligent FLC used in this piece of work was proposed by Hector et.al [10] as new methodology of self-organizing FLC able to adapt online its own parameters using only some qualitative information. The following sections describe the methodology of this intelligent FLC.

Before starting the description of the methodology of the intelligent controller, the immense tools that bring this controller must be mentioned:

- The mathematical model of the controlled plant is not required at all; also, the differential equations are not necessary.

- The intelligent FLC initiates the control of the plant with no rule base or by allocating arbitrary values.

- The intelligent FLC is very robust against disturbances, i.e., its able to adjudicate the new state imposed by the disturbance and compensate their negative effects on the control process.

Thus, to initiate a control process, the controlled plant should be described mathematically by an equivalent model. Generally, a common model of controlled plant can be presented like:

$$
g(l+\tau)=f(g(l), \ldots, g(l-\alpha), v(l), \ldots, v(l-\beta))
$$

where $\tau$ is the delay of the controller system and $\mathrm{f}$ is an unknown continuous and derivable function. The time delay is considered as a determinist factor to achieve the maximum performance in the majority of the engineering process, for example: electrical distribution applications, signals processing, etc. The dilemma of the crucial role of the time delay was very well documented over the last decade [10], [11], [12], and [13]. In order to use the intelligent FLC, the controlled process should have an adequate delay time and the plant should be continuous and presents a constant monotonicity, i.e. the relation between the controlled process and the controller output has the same sign. The Intelligent FLC is based essentially on adapting the fuzzy rules. Throughout two stages of self-adaptation the controller can adjust en reel time their own parameters to follow the reel need of the plant and to predict the convenient output. The only information used from the system is its monotonicity sign and its delay to perform a coarse adaptation of the fuzzy rules (consequents adaptation and antecedents adaptation).
For the consequents adaptation, the evaluation of the current state of the plant leads to impose a correction of the rules responsible for the actual state of the plant. The sense of the imposed correction is deduced from the monotonicity of the plant as reward or penalty. Equation (9) presents the expression of the proposed correction:

$$
\begin{aligned}
\Delta S_{j_{1} j_{2} \cdots j_{N}}(l)=Q \cdot \gamma_{j_{1} j_{2} \cdots j_{N}}(l-\lambda) \cdot e_{g}(l) \\
Q \cdot \gamma_{j_{1} j_{2} \cdots j_{N}}(l-\lambda) \cdot(s(l-\lambda)-g(l))
\end{aligned}
$$

where $\gamma_{j_{1} j_{2} \cdots j_{N}}$ is the strength or $\alpha$-level of rule $S_{j_{1} j_{2} \cdots j_{N}}$

$e_{g}(l)$ is the error at instant $l$.

The $Q$ coefficient is an absolute value that should be computed offline, where: $|Q|=\Delta u / \Delta g$.

$\Delta g$ represents the output space of the controlled plant and $\Delta u$ is the operation interval of the actuator.

In [13], the evaluation of the proposed modification is done at the instant $l$ using proportionally the activation degree of the rule responsible of the plant output $u(l-\lambda)$ at the instant $(l-\lambda)$. It's very important to highlight here that if $s(l-\lambda)$ was used instead $s(l)$ it would be wrong because at the instant $l-\lambda$ a set of rules was activated to achieve the set point $s(l-\lambda) \operatorname{not} s(l)$.

As it is mentioned above, the intelligent FLC starts the adjustment of their internal parameters through adapting the consequents of the rules by applying rewards or penalties. After that, its tackles the second step through the reorganization of the membership functions in the inputs spaces to equilibrate the accumulated error that results from the adaptation process. Hence, the new rules antecedents will represent more faithfully the actual state of the controlled system.

In order to establish a balanced input space regarding the accumulated error during the first stage of learning process, the intelligent FLC incorporates an autonomous tools that can ensure the equilibrium on the registered error over different areas of the input spaces by redistributing the membership functions to make the areas with an important error accumulation covered by more membership functions so as to compensate it. Since, the area with an important accumulation of error is the most activated area during the control process. Hence, it should be well expressed by enough membership functions. The criterion that represents the accumulated error is the Integral of squared error and it's calculated by as follow:

$$
\begin{array}{r}
I S E_{i}^{j}=\frac{1}{\sigma_{y}^{2}}\left(\left.\int e^{2}(t) d t\right|_{z_{i}(t) \epsilon\left[p_{i}^{j-1}, p_{i}^{j}\right]}\right. \\
\left.-\left.\int e^{2}(t) d t\right|_{z_{i}(t) \epsilon\left[p_{i}^{j}, p_{i}^{j+1}\right]}\right)
\end{array}
$$

In the aforementioned expression, $\mathrm{z}_{\mathrm{i}}(\mathrm{t})$ represents the input while pi represents the $j$-th membership function center and $\sigma_{\mathrm{y}}^{2}$ is a normalization factor that represents the variance of the 
plant output. The two integrals calculate the error in two cases, the first one in the case when the input is between $(j-1)$ and $j$ centers and the second one in the case when the input is between $j$ and $(j+l)$ centers. It's to note here that the system is discrete that's mean the integral can be expressed as a sum, so the equation can be simplified. The result of this sum can precise in which side the center of the membership function should be moved, hence, when the sum is positive, that means the error in the right was smaller than in the left. Therefore, the center has to be moved to the left to minimize the accumulated error in this area. Otherwise, when the sum is negative the center should be moved to the right. This displacement of membership functions centers should not affect their original order. The displacement of the membership function centers is ensured by the following expression:

$$
\Delta p^{j}= \begin{cases}\frac{p^{j-1}-p^{j}}{2} \frac{I S E^{j}}{I S E^{j}+\frac{1}{S^{j}}}, & \text { if } I S E^{j} \geq 0 \\ \frac{p^{j+1}-p^{j}}{2} \frac{\left|I S E^{j}\right|}{\left|I S E^{j}\right|+\frac{1}{S^{j}}}, & \text { if } I S E^{j}<0\end{cases}
$$

where, the distance that can a center of a membership function be moved on without over passing the permitted limits is expressed by $S^{j}$. Therefore, big value of $S^{j}$ implies an important displacement of the membership function center and small value of $S^{j}$ implies a short displacement of this centre. The sum of the accumulated error will be computed during an enough predefined time $T$ and the intelligent controller starts the operation with a big value of $S^{j}$ to ensure an important displacement of the centers over the inputs spaces, the initial value of $S^{j}$ will be exponentially decreased by time. The learning process of the intelligent controller starts until the second run. Hence, at the first run the controller proceed to tune their rules consequents and the ISE is not calculated yet. The end of the second run brings the modification of the emplacements of the membership functions centers. So, at the upcoming time $T$ the controller will not compute the ISE and will proceed to re-tune their rules consequents according to the new centers emplacement. For every time the controller needs to compute a new ISE it will use a $S^{j}$ value smaller than the value used previously.

\section{THE RESUlts OF THE HUMIDITy CONTROL PROCESS}

The goal of these papers is not only the presentation of a control algorithm able to replace the On/Off method used actual inside the electric cells to avoid high levels of moisture that provokes serious damage on the electrical devices and power failures. But, the main goal was the limitation of wastage of energy during the humidity control process. Since, the dew point inside the cells is avoided by implementing a set of heating resistances that need an important amount of electrical energy to heat the internal surroundings. These latter don't need a high control precision to ensure the desired conditions.

Therefore, there are a lot of used controllers that can guaranty these criterions but not the limitation of wastage of energy. For this reason the use of the Intelligent FLC previously presented is proposed. The Intelligent FLC is a powerful control algorithm that presents several interesting control quality like: High precision, robustness against perturbation and low power consumption during the control process [14].

To present the valuable contribution that brings the intelligent controller on the energy consumption while controlling the humidity inside the electric cells we proceed to present the obtained results of different control process using firstly the On/Off controller actually used by the electricity distribution company. Secondly, a conventional Fuzzy Logic Controller (FLC) will be used in the same control process to make out the control performances regarding the energy consumption and finally the intelligent FLC will be implemented under the same conditions as the beforehand mentioned control processes. So that, we can easily highlight the effects of each one of the used controllers on the energy consumption to precise the most effective one. Table $\mathrm{V}$ presents the real consumption of the heating resistances installed inside the electric cells using the On/Off controller. It's to note here that the electric cells situated to close to the sea need more powerful resistances than other cells.

TABLE V. The Details of REAL CONSUMPTION OF THE HEATING RESISTANCES USING THE ON/OFF CONTROLLER

\begin{tabular}{ccccc}
\hline \hline & $\begin{array}{c}\text { Power of the } \\
\text { heating } \\
\text { resistance in } \\
\text { Watt }\end{array}$ & $\begin{array}{c}\text { Number of } \\
\text { resistances }\end{array}$ & $\begin{array}{c}\text { Daily } \\
\text { consumption } \\
\text { in KWh }\end{array}$ & $\begin{array}{c}\text { Annual } \\
\text { consumption } \\
\text { in KWh }\end{array}$ \\
\hline $\begin{array}{c}\text { Close to } \\
\text { the sea }\end{array}$ & 50 & 3 & 3,6 & 1.314 \\
$\begin{array}{c}\text { Far from } \\
\text { the sea }\end{array}$ & 100 & 3 & 7,2 & 2.628 \\
\hline \hline
\end{tabular}

Fig. 7 presents the evolution of the supply signal regarding the temperature inside the electric cell using the On/Off controller. This kind of controller starts the control process using the maximum of power feeding and keeps the supply signal constant until reaching the desired point. Therefore, the sum of the power consumed during this period will be very important.

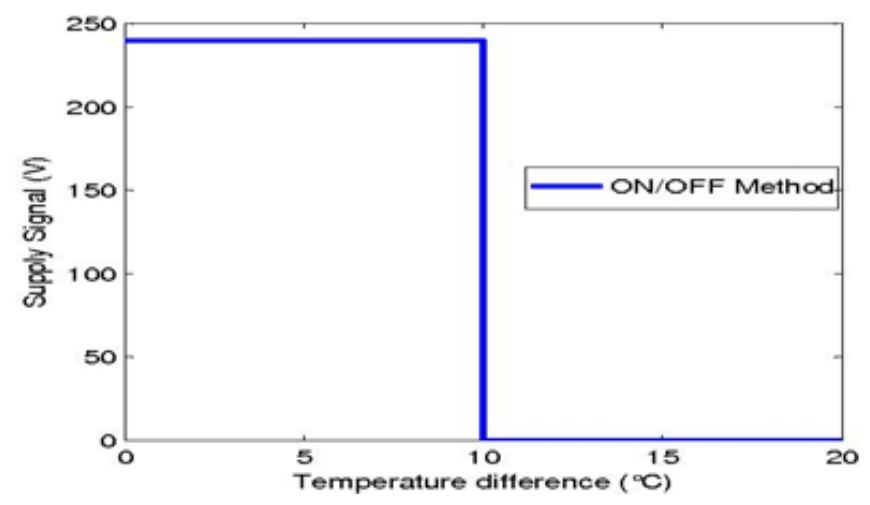

Fig. 7. The evolution of the supply signal regarding the temperature inside the electric cell using the On/Off controller

Trying to improve the control process performances vis-avis the power consumption, a conventional FLC was used and 
the obtained results show that the energy balance of the control process can be improved with a significant gain in electrical energy. Fig. 8 presents the evolution of the supply signal regarding the temperature inside the electric cell using the conventional FLC versus the On/Off controller.

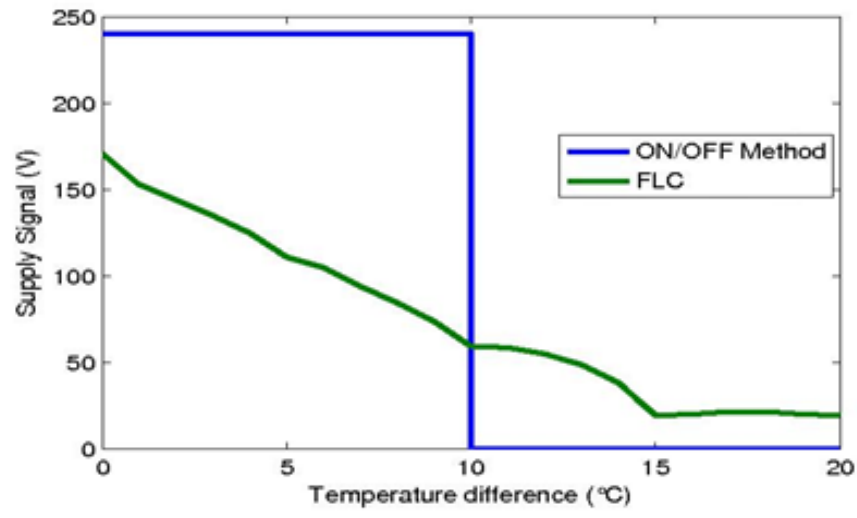

Fig. 8. The evolution of the supply signal regarding the temperature inside the electric cell using the conventional FLC versus the On/Off controller

The above figure can explain clearly that unlike the On/Off controller, the conventional FLC starts the control with a relatively small voltage and decreases this value proportionally with the registered temperature until achieving the desired temperature then the power supply will be stabilized even if the inside temperature is upper that the dew point. This operating mode generates relatively low power consumption over the time. Since, the FLC doesn't use the maximum voltage and decrease the used power by time. Hence, the sum of the power consumed during the control process will be reasonable compared to the On/Off controller.

As it's mentioned above, the control of the humidity inside the electric cells doesn't need high control precision. Nevertheless, another criterion plays a fundamental role in this control process. The challenge faced on during this process is the power consumed. Starting from the fact that the energy production has an important and direct impact on the environment - the majority of the electrical energy consumed comes from polluting sources - we are strongly concerned about how can we reduce and the optimize of our electrical energy needs. In this control process, the Intelligent FLC used has been able to carry out a very precise control process with an amazing energy balance. Fig. 8 describes the evolution of the supply signal regarding the temperature inside the electric cell using the intelligent FLC versus the remaining used controllers.

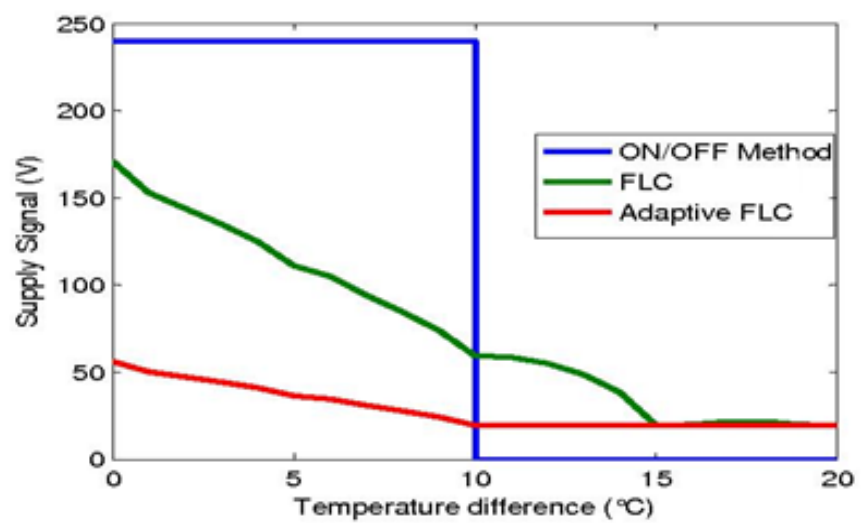

Fig. 9. The evolution of the supply signal regarding the temperature inside the electric cell using the Intelligent FLC versus the remaining used controllers

The Intelligent FLC starts the control by generating a moderated supply signal to ensure the temperature increase until reaching the safe value then the supply signal will be stabilized. Generally, the needed power to ensure this control process is very lower than the power needed using the remaining controllers. Since, the intelligent FLC begin with a smaller voltage and decreases it by the time until the stabilization at a small voltage keeping the heating resistances powered permanently. This advantage serve to optimize the energy needed to restart the heating process without requiring too much energy as in the On/Off controller and better than the conventional FLC. Table VI presents the real consumption of the heating resistances installed inside the electric cells using the On/Off controller, the conventional FLC and the Intelligent FLC.

TABLE VI. THE REAL CONSUMPTION OF THE HEATING RESISTANCES USING DIFFERENT CONTROLLER

\begin{tabular}{c|cccccc}
\hline & \multicolumn{2}{c}{ On/Off } & \multicolumn{2}{c}{ FLC } & \multicolumn{2}{c}{ Intelligent FLC } \\
\hline & $\begin{array}{c}\text { Close } \\
\text { to the } \\
\text { sea }\end{array}$ & $\begin{array}{c}\text { Far } \\
\text { from } \\
\text { the sea }\end{array}$ & $\begin{array}{c}\text { Close } \\
\text { to the } \\
\text { sea }\end{array}$ & $\begin{array}{c}\text { Far } \\
\text { from } \\
\text { the sea }\end{array}$ & $\begin{array}{c}\text { Close } \\
\text { to the } \\
\text { sea }\end{array}$ & $\begin{array}{c}\text { Far } \\
\text { from } \\
\text { the sea }\end{array}$ \\
\hline $\begin{array}{c}\text { Daily } \\
\text { consumption } \\
\text { in KWh } \\
\begin{array}{c}\text { Annual } \\
\text { consumption } \\
\text { in KWh }\end{array}\end{array}$ & 3,6 & 7,2 & 3,2 & 6,9 & 2,7 & 6,7 \\
\hline \hline
\end{tabular}

The daily and annual energy consumption of the three used controllers illustrates the efficiency of the Intelligent FLC in 
terms of energy saving. The use of this latter can guarantee the saving of an important amount of the energy consumed by the resistances using the On/Off controller. Knowing that in the electrical distribution network, thousands of electric cells are installed. The sum of the energy saved in each one will be a huge gain in terms of energy and money.

\section{CONCLUSION}

Nowadays, the energy and the climate changes represent an extremely important issue for the whole word. Since, the energy production usually comes from processes that affect the environment. For that, the energy saving has become the centre of interest in several research areas. This work pretend to present a new idea to reduce the energy consumption over the huge electrical power distribution networks by reducing the important energy consumed while protecting thousands of electric cells from the damage caused by the moisture. Actually the controller used to control the heating resistances installed inside the electric cells is an On/Off controller that can ensure the ideal temperature to protect the cells from moisture, but with an important waste of energy. The Intelligent Fuzzy Logic Controller that we propose to use has demonstrated that can be a very suitable alternative to protect the cells and in the same time ensure an important reduction in the power consumption that can be reflected in the electric bills. Thus, the environmental cost of energy production will be on the wane. The presented results illustrate the effectiveness of this controller compared with the On/Off controller and even the conventional FLC.

\section{REFERENCES}

[1] B. Khalil, J. Adamowski, A. Shabbir, C. Jang, M. Rojas, K. Reilly Bogdan, Ozga-Zielinski, "A review: dew water collection from adiative passive collectors to recent developments of active collectors: Sustain". Water Resour. Manag, Vol.2, pp. 71-86, 2016.

[2] O. O. Adeoye, L. E. Shephard, M. Wright, Moses West, Stacy Peters, "Atmospheric Water Generation: A Path to Net-Zero", 2016 IEEE Green Technologies Conference, pp. 45-50, April 2016.
[3] Maisarah Ali et al., "Hygrothermal Performance of Building Envelopes in the Tropics Under Operative Conditions: Condensation and Mould Growth Risk Appraisal”, Jurnal Teknologi (Sciences \& Engineering) 87:5, pp.271-279, 2016.

[4] Milton Ohring, Lucian Kasprzak, "Reliability and Failure of Electronic Materials and Devices", / Chapter 7, 2nd Edition Elsevier, ISBN9780120885749

[5] Kallias, AN, Imam, B and Chryssanthopoulos, MK, "Performance profiles of metallic bridges subject to coating degradation and atmospheric corrosion", Structure and Infrastructure Engineering: maintenance, management, lifecycle design and performance, 2016.

[6] Tony Byrne, "Humidity effects in substations", 2014 Petroleum and Chemical Industry Conference Europe, p. 1-10, June 2014.

[7] Baghban, A, Bahadori, M, Rozyn, J, Lee, M, Abbas, A, Bahadori, A and Rahimali, A, "Estimation of air dew point temperature using computational intelligence schemes", Applied Thermal Engineering, vol. 93, pp. 1043-1052, 2015.

[8] Kasra Mohammadi et,al. "Using ANFIS for selection of more relevant parameters to predict dew point temperature", Applied Thermal Engineering,Vol. 96, pp. 311-319, 2016.

[9] Jinbo Zhang, Tongguang Shao, Yu Wang, Jing Wang, "A New Type of Dehumidifier for Enclosed High-voltage Switchgear Cabinet", TELKOMNIKA, Vol. 10, No. 7, November 2012.

[10] H. Pomares, I. Rojas, J. González, F. Rojas, M. Damas and F. J. Fernández "A two-stage approach to selflearning direct fuzzy controllers," International Journal of Approximate Reasoning, Vol. 29, Issue 3, pp. 267-289, 2002.

[11] I. Rojas, H. Pomares, F.J. Pelayo, M. Anguita, E. Ros, A. Prieto, "New methodology for the development of adaptive and self-learning fuzzy controllers in real time," International Journal of Approximate Reasoning, vol. 21, pp. 109-136, 1999.

[12] Chen Peng, Li-Yan Wen, and Ji-Quan Yang, "On Delaydependent Robust Stability Criteria for Uncertain T-S Fuzzy Systems with Interval Time-arying Delay," International Journal of Fuzzy Systems, Vol. 13, No. 1, Mar 2011.

[13] A. Boulkroune, M. M'Saad, M. Farza, "Adaptive fuzzy controller for multivariable nonlinear state time-varying delay systems subject to input nonlinearities," Fuzzy sets and systems, Vol. 164, No. 1, pp. 45- 65, Feb 2011.

[14] R. Lasri, I. Rojas, H. Pomares and O. Valenzuela, "Innovative Strategy to Improve Precision and to Save Power of a Real-Time Control Process Using an Online Adaptive Fuzzy Logic Controller, "Advances in Fuzzy Systems, Vol. 2013, pp. 16, Article ID 658145. 